\title{
Dorsal Neck Muscle Fatigue Affects Cervical Range of Motion and Proprioception in Adults with the Forward Head Posture
}

\author{
Sang-Seok Yeo, Jung-Won Kwon \\ Department of Physical Therapy, College of Health \& Welfare, Dankook University, Cheonan, Republic of Korea
}

Purpose: This study was to investigate the effect of dorsal neck muscle fatigue on the cervical range of motion (CROM) and proprioception in adults with the forward head posture (FHP).

Methods: Thirty pain-free subjects were enrolled in this study. All subjects were measured the forward head angle by taking the capture of the sagittal plane of their upper body to determine the FHP. Subjects were distributed into two groups: the FHP group $(n=14)$ and Control group $(n=16)$. All subjects were measured the CROM and the Head repositioning accuracy (HRA) for joint proprioception before and after inducing muscle fatigue of the dorsal neck. The CROM and HRA were measured in neck flexion, extension, right-left lateral flexion, and right-left rotation. Sorenson's test was used to induce muscle fatigue of the dorsal neck.

Results: Total CROMs were significantly decreased after dorsal neck muscle fatigue in both groups $(p<0.05)$. Total HRAs were significantly increased after dorsal neck muscle fatigue in the FHP group $(p<0.05)$, but there were no significant differences in the control group ( $p>0.05)$. Total CROM changes were not significant differences between groups ( $p>0.05)$, but total HRA changes were significant differences between groups $(p<0.05)$ except for right and left lateral flexion $(p>0.05)$.

Conclusion: Immediate CROM and proprioception reduction after the dorsal neck muscle fatigue were observed in adults with the FHP. Therefore, FHP can significantly affect the CROM and positioning consistency of cervical proprioception.

Keywords: Muscle fatigue, Forward head posture, Proprioception, Range of motion

\section{서 론}

앞쪽머리자세는 신체에 스트레스와 긴장을 최소한으로 유지하는 상 태에서 머리를 앞으로 움직였을 때, ${ }^{1}$ 균형을 유지하기 위해 아래 목뼈 의 과도한 앞굽음과 위 등뼈의 과도한 뒤굽음이 유발된 상태로, ${ }^{2}$ 신 체의 중력중심선을 기준으로 앞쪽에 위치해 있다.1,34 머리를 앞쪽으 로 유지한 자세를 장시간 취할 경우 윗 목빼 주변의 폄근 토크가 증가 하고 척추의 하중이 증가한다. ${ }^{5}$ 또한 목척추의 비수축성 구조에 대한 하중이 증가하고 목뼈의 뒤쪽 구조물에 비정상적인 스트레스를 가 한다. ${ }^{6}$ 앞쪽머리자세는 근육 불균형, 통증, 피로, 목뼈의 제한된 움직 임, 턱관절 장애, 어깨뼈의 비정상적 상태와 같은 근골격계 문제를 일 으켜 근육의 효율성을 감소시킨다. 4.78 또한, 목과 어깨 부위의 근육에 긴장도과 스트레스를 증가시켜 머리와 목의 균형 잡힌 자세를 유지 하기 위해서는 추가적인 근육의 활성화가 필요하다. 특히 앞쪽머리
자세가 나타나기 시작하면 목 통증과 같은 근골격계 질환에 의해 근 육에 피로가 생기게 되고 고유수용성 감각이 떨어지며, 근육 활성화 패턴이 변경된다.9

일반적으로 근육 피로는 운동 기능을 손상시킬 수 있는 급성 효과 의 단계를 의미하며, ${ }^{10}$ 집중적으로 반복되는 최대 수축의 결과로 발 생하거나 더 오랜 기간 동안 최대 이하의 수축을 반복하여 발생한다. ${ }^{6}$ 근육 피로는 근육의 최대 힘을 점진적으로 감소시켜 일상생활 동작 을 방해하고, 신체 활동이나 개인의 작업 능률을 떨어뜨린다.611 또한, 근육 반사 활동을 변경하고, 척추 전체의 경직도를 조절하기 위한 공 동 활성화를 증가시켜 근육 동원을 변경시킨다.12 머리를 앞쪽으로 기 울이는 앞쪽머리자세가 장기간 유지될 경우 수축-이완이 감소하여 목 주변 근육의 피로가 급격히 증가한다. ${ }^{13}$ 이러한 목 근육의 피로는 목 근육의 감각 수용체의 역할을 수정하고, ${ }^{14-17}$ 고유수용성 감각에 영향을 미친다. ${ }^{18}$ 근육 기능의 손상이 목 뒤쪽의 안정구조와 깊은목
Received Oct 12, 2020 Revised Oct 15, 2020

Accepted Oct 20, 2020

Corresponding author Jung-Won Kwon

E-mail wnddnjsl03@naver.com
Copylight (C)2020 The Korean Society of Physical Therapy

This is an Open Access article distribute under the terms of the Creative Commons Attribution Non-commercial License (https:// creativecommons.org/license/by-nc/4.0.) which permits unrestricted non-commercial use, distribution, and reproduction in any medium, provided the original work is properly cited. 
굽힘근 사이에 불균형을 만들어 적절한 정렬과 자세가 상실될 수 있 고, 이것은 통증 증가, 근력 감소 및 위치 감각 변경과 같은 목뼈의 손 상을 야기할 수 있다. ${ }^{14}$

근육 피로는 구심성 피드백을 변경할 수 있으며, 감각 수용체의 역 할을 바꾸고, 고유수용성 감각에 정확도를 감소시켜 관절 위치 감각 에 영향을 미친다.6,14,17 목 근육의 고유수용성 감각 입력은 안뜰계에 작용하여 신체의 적절한 방향, 균형 및 운동 협응을 유지하고, 시각적 물체의 움직임과 위치를 감지하는 데 중요한 역할을 한다.16,18 앞쪽머 리자세로 인해 목 주변 근육의 피로가 생기고, 고유수용성 반사작용 이 약화되어 척추의 불안정성 및 손상의 위험을 증가시킨다.13,19 선행 연구에 따르면 고유수용성 감각을 목표로 하는 치료가 목의 관절 위 치 감각을 향상시키고 통증을 감소시킨다고 보고하였다. ${ }^{20}$ 또한 눈 머리의 협응을 기초로 한 운동 프로그램이 목뼈의 운동 이상을 개선 하고 목뼈의 통증을 감소시킨다고 보고하였으며, ${ }^{21}$ 시선 안정 운동, 깊은목굽힘근과 목굽힘근의 협응을 훈련에 관한 연구도 보고되었 다.22 또 다른 선행 연구에서는 눈-머리 협응 운동, 몸통에서의 머리 재배치 연습이 머리 재배치 정확도가 크게 향상되었다고 보고하였 다.23 이와 같이 목 척추의 위치 감각이나 고유수용성 감각, 통증에 대 한 연구뿐만 아니라 근육 피로 유발 후 근활성도에 대한 연구는 많이 이루어져 왔지만, 앞쪽머리자세를 가진 사람의 고유수용성 감각에 대한 연구 및 근육 피로 유발 후 관절가동범위나 고유수용성 감각에 대한 연구는 부족한 실정이다. 따라서 본 연구는 앞쪽머리자세의 유 무에 따라 목의 근육 피로를 유발한 후 목의 관절가동범위와 고유수 용성 감각의 변화를 알아보고자 한다.

\section{연구 방법}

\section{1. 연구대상}

본 실험은 젊은 성인 30 명을 모집하였고, 앞쪽머리자세의 유무에 따 라 앞쪽머리자세를 가진 성인을 $\mathrm{FHP}$ 군, 정상 성인을 정상군으로 설 정하였다. 앞쪽머리자세 판정은 선행연구에 따라 사진측정 방법을 이용하여 머리-척추각이 $54^{\circ}$ 이하인 경우 앞쪽머리자세라고 판정하 였으며, FHP군으로 선정하였다. FHP군의 일반적 특성으로 평균 연 령은 22.7 세, 평균 신장은 $169.8 \mathrm{~cm}$, 평균 체중은 $66.9 \mathrm{~kg}$, 평균 머리-척 추각은 $48.8^{\circ}$ 이고, 정상군에서 평균 연령은 21.5세, 평균 신장은 161.6 $\mathrm{cm}$, 평균 체중은 $53.1 \mathrm{~kg}$, 평균 머리-척추각은 $61.0^{\circ}$ 이다. 현재 목과 어 깨에 통증이 있는 사람, 목뼈와 가슴뼈에 근골격계 질환이 있는 사 람, 활동을 제한하는 신경학적 장애가 있는 사람은 연구대상에서 제 외하였다. 모든 대상자들은 실험 전에 충분한 설명을 듣고 실험에 동 의하였으며, 자발적으로 참여하였다.

\section{2. 실험방법}

\section{1) 앞쪽머리자세의 머리-척추각}

앞쪽머리자세를 판정하기 위해 대상자들의 측면을 촬영한 사진을 이용하였다. 카메라는 의자로부터 $3.5 \mathrm{~m}$ 떨어져 있으며 $1 \mathrm{~m}$ 높이의 삼 각대에 위치하였다. 대상자를 의자에 앉게 하고, 편안한 자세를 취하 라고 하였다. 사진에서의 머리-척추각 판정을 위해 귀의 이주와 제7 목뼈 가시돌기 위 피부에 표시점을 부착하였다. 머리-척추각은 귀의 이주와 제 7 목뼈 가시돌기를 연결한 선과 제 7 목빼 가시돌기를 지나 가는 수평선 사이의 각도를 의미하는데, ${ }^{4}$ 각도가 작을수록 앞쪽머리 자세가 심하다는 것을 의미한다. 선행연구에 따르면 머리-척추각을 이용한 앞쪽머리자세의 신뢰도는 높았다(ICC $=0.08){ }^{24}$

\section{2) 목 관절가동범위 측정}

목의 관절가동범위를 MicroFET6 (Hoggan, USA)를 이용하여 측정하였 다. MicroFET6는 시작자세의 각도와끝 자세 각도의 차이 값을 나타내 는 측정기로, 고정 축을 제 1 가슴뼈에, 운동 축을 정수리에 놓고 측정 하였다. MicroFET6가 머리에서 미끄러지는 것을 방지하기 위하여 헤어 밴드를착용하게 하였다. 측정 항목은 목 굽힘, 폄, 양측 옆굽힘, 양측 회 전이며, 각 항목의 측정 순서는 무작위로 시행하였다. 목의 양측 회전 을 제외한 모든 측정항목들은 대상자를 등받이가 있는 의자에 상체 를 바로 세워 앉힌 후, 어깨관절을 이완하고 손을 무릎에 놓게 한 상태 에서 측정하였다. 목 굽힘 측정 시 대상자의 턱을 가슴 쪽으로 최대한 당기게 하였고, 목 폄 측정 시 대상자의 목을 최대한 뒤로 젖히게 하여 측정하였다. 목 양측 옆굽힘 측정 시에는 옆굽힘 하고자 하는 방향으 로 대상자의 귀가 어깨에 최대한 닿도록 목을 기울이게 하여 측정하였 다. 이때, 측정자는 양측 옆굽힘이 제한되었을 때 어깨를 들어 올려 귀 에 닿게 하려는 보상운동을 막기 위해 양쪽 어깨를 고정하였다. 목의 양측 회전 관절가동범위는 대상자를 바로 눕게 하고, 회전하고자하는 방향의 턱을 어깨선에 최대한 도달하도록 하여 측정하였다. 측정값은 각측정 항목당 3 번씩 시행한 후 평균값을 기록하였다

\section{3) 고유수용성 감각 측정}

머리의 위치와 동작을 감지하는 능력을 평가하여 고유수용성 감각 변화를 보기 위해 머리 재배치 정확도(head repositioning accuracy, $\mathrm{HRA}$ )를 사용하였다.25,26 대상자를 벽에서 $90 \mathrm{~cm}$ 떨어진 등받이가 있 는 의자에 앉히면서 레이저가 붙어있는 헬멧을 머리에 쓰게 하고, 목 의 최대 굽힘과 최대 폄을 한 후 중립자세를 취하게 하였다. 이 때 벽 에 부착된 모눈종이에 레이저가 위치한 점을 표시하고, 대상자의 눈 을 감게 한 후 목을 굽힘시키고, 다시 원래 위치로 오게 하였다. 이 때 레이저가 위치한 점을 표시하여 처음 점과의 거리 차이를 측정하고, 10 번 반복하여 평균값을 기록하였다. 마찬가지로 목 폄, 양측 옆굽힘, 
양측 회전 동작 또한 각각 10 번 반복 측정하여 평균값을 기록하였다. 측정순서는 무작위로 시행하였다.

\section{3. 실험절차}

판정을 위한 사진촬영 후, 대상자들의 목 관절가동범위와 고유수용 성 감각을 측정하였다. 그 다음, 목에 근피로도를 유발하기 위하여 여 러 선행 연구에서 대표적인 방법으로 이용된 Sorensen test를 이용하 였다. ${ }^{27,28}$ 근피로도를 주기 위하여 대상자들을 테이블에 엎드려 눕힌 후, 양 팔은 몸 옆에, 테이블 끝에는 어깨의 봉우리를 위치시켰다. 머 리와 목 부위는 근피로도 유발을 위해서 중력의 영향을 받도록 테이 블 밖으로 내민 자세를 유지하게 하였다. 이 자세를 유지하는 동안 근 피로로 인한 불편함의 정도를 평가하기 위하여 Borg CR-10 scale을 사 용하였다. 대상자는 머리와 목 부위를 내민 자세로 가능한 오래 유지 하게 하였으며, 대상자의 과도한 근피로와 손상의 위험을 방지하기 위해 Borg CR-10 scale이 8점 일 때 자세를 중단시켰다. 모든 대상자는 Sorensen test 직후에 목 관절가동범위와 고유수용성 감각을 다시 측 정하였다. 모든 실험 절차는 근피로도에 영향을 미치는 외적 요인들 을 최소화하기 위하여 오전에 실시하였다.

\section{4. 자료분석}

모든 자료는 기술통계를 이용하여 평균과 표준편차로 제시하였으며 정규성 검정을 실시하였다. 목의 근피로도 유발 전과 후 목의 관절가 동범위와 고유수용성 감각의 변화에 대한 집단 내 비교를 위하여 대 응표본 $\mathrm{t}$ 검정을 실시하였고, 목의 근피로도 유발 전과 후 목의 관절가 동범위와 고유수용성 감각의 변화량을 집단 간 비교하기 위하여 독 립표본 $\mathrm{t}$ 검정을 실시하였다. 자료분석은 SPSS 22.0 for Window 통계 프 로그램을 사용하였고, 통계학적 유의수준은 $\alpha=0.05$ 로 설정하였다.

\section{결 과}

\section{1. 목의 근피로도 유발 전후 집단 내 관절가동범위와 고유수용성 감각 비교}

목의 근피로도를 유발하기 전과 후 목의 관절가동범위를 비교한 결 과 $\mathrm{FHP}$ 군과 정상군 모두 모든 동작에서 유의하게 감소하였다 $(\mathrm{p}<0.05)$. 목의 근피로도를 유발하기 전과 후 목의 고유수용성 감각 을 비교한 결과 FHP군에서는 모든 동작에서 유의하게 감소하였지만 $(\mathrm{p}<0.05)$, 정상군에서는 유의한 차이가 없었다 $(\mathrm{p}>0.05)($ Table 1$)$.

Table 1. Changes of cervical range of motion (CROM) and proprioception after dorsal neck muscle fatigue in each group

\begin{tabular}{|c|c|c|c|c|c|c|}
\hline Group & Measurement & Movement & Pre-test & Post-test & $\mathrm{t}$ & $\mathrm{p}$ \\
\hline \multirow[t]{12}{*}{ Experimental group } & \multirow[t]{6}{*}{$\operatorname{CROM}\left({ }^{\circ}\right)$} & Flexion & $62.20 \pm 8.59$ & $51.93 \pm 9.80$ & 4.087 & $0.001^{*}$ \\
\hline & & Extension & $59.08 \pm 14.96$ & $48.67 \pm 13.15$ & 3.609 & $0.003^{*}$ \\
\hline & & Rt Flexion & $50.23 \pm 8.48$ & $44.30 \pm 10.29$ & 4.346 & $0.001^{*}$ \\
\hline & & Lt Flexion & $48.54 \pm 9.82$ & $41.81 \pm 9.59$ & 3.576 & $0.003^{*}$ \\
\hline & & Rt Rotation & $74.37 \pm 8.33$ & $67.65 \pm 9.65$ & 3.550 & $0.003^{*}$ \\
\hline & & Lt Rotation & $73.23 \pm 8.71$ & $67.29 \pm 9.60$ & 4.869 & $<0.001^{*}$ \\
\hline & \multirow[t]{6}{*}{$\mathrm{HRA}(\mathrm{cm})$} & Flexion & $5.28 \pm 1.62$ & $6.80 \pm 2.03$ & -4.011 & $0.001^{*}$ \\
\hline & & Extension & $5.05 \pm 1.82$ & $6.51 \pm 1.87$ & -2.816 & $0.013^{*}$ \\
\hline & & Rt Flexion & $4.96 \pm 1.13$ & $6.04 \pm 1.64$ & -2.599 & $0.020^{*}$ \\
\hline & & Lt Flexion & $5.10 \pm 2.00$ & $6.50 \pm 1.84$ & -2.565 & $0.022^{\star}$ \\
\hline & & Rt Rotation & $5.19 \pm 1.47$ & $6.60 \pm 2.20$ & -2.285 & $0.037^{\star}$ \\
\hline & & Lt Rotation & $5.38 \pm 2.45$ & $6.47 \pm 2.40$ & -2.352 & $0.033^{*}$ \\
\hline \multirow[t]{12}{*}{ Control group } & \multirow[t]{6}{*}{$\operatorname{CROM}\left({ }^{\circ}\right)$} & Flexion & $56.76 \pm 11.94$ & $47.36 \pm 10.30$ & 5.076 & $<0.001^{*}$ \\
\hline & & Extension & $54.19 \pm 17.07$ & $48.50 \pm 13.79$ & 2.848 & $0.014^{*}$ \\
\hline & & Rt Flexion & $47.76 \pm 7.88$ & $41.50 \pm 7.35$ & 6.765 & $<0.001^{*}$ \\
\hline & & Lt Flexion & $48.26 \pm 8.90$ & $44.20 \pm 6.49$ & 3.292 & $0.006^{*}$ \\
\hline & & Rt Rotation & $75.15 \pm 11.16$ & $67.05 \pm 13.38$ & 3.933 & $0.002^{*}$ \\
\hline & & Lt Rotation & $76.30 \pm 6.90$ & $67.60 \pm 11.38$ & 4.856 & $<0.001^{*}$ \\
\hline & \multirow[t]{6}{*}{$\mathrm{HRA}(\mathrm{cm})$} & Flexion & $5.13 \pm 1.71$ & $5.41 \pm 1.73$ & -0.616 & 0.549 \\
\hline & & Extension & $4.77 \pm 1.25$ & $4.84 \pm 1.51$ & -0.235 & 0.818 \\
\hline & & Rt Flexion & $5.64 \pm 2.41$ & $5.56 \pm 2.29$ & 0.159 & 0.876 \\
\hline & & Lt Flexion & $5.49 \pm 2.44$ & $5.33 \pm 3.02$ & 0.285 & 0.780 \\
\hline & & Rt Rotation & $5.68 \pm 1.75$ & $5.32 \pm 1.79$ & 1.779 & 0.099 \\
\hline & & Lt Rotation & $5.91 \pm 3.28$ & $5.43 \pm 2.24$ & 0.839 & 0.416 \\
\hline
\end{tabular}


Table 2. The comparison of pre-post changes of cervical range of motion (CROM) and proprioception after dorsal neck muscle fatigue between groups

\begin{tabular}{|c|c|c|c|c|c|}
\hline Measurement & Movement & Experimental group & Control group & $\mathrm{t}$ & $\mathrm{p}$ \\
\hline \multirow[t]{6}{*}{$\operatorname{CROM}\left({ }^{\circ}\right)$} & Flexion & $-10.28 \pm 10.06$ & $-9.41 \pm 6.93$ & 0.027 & 0.787 \\
\hline & Extension & $-10.12 \pm 11.55$ & $-5.69 \pm 7.48$ & 1.309 & 0.201 \\
\hline & Rt Flexion & $-5.94 \pm 5.47$ & $-6.26 \pm 3.47$ & -0.191 & 0.850 \\
\hline & Lt Flexion & $-6.73 \pm 7.52$ & $-4.07 \pm 4.63$ & 1.145 & 0.262 \\
\hline & Rt Rotation & $-6.73 \pm 7.58$ & $-8.10 \pm 7.71$ & -0.493 & 0.626 \\
\hline & Lt Rotation & $-5.94 \pm 4.88$ & $-8.79 \pm 6.77$ & -1.334 & 0.193 \\
\hline \multirow[t]{6}{*}{ HRA $(\mathrm{cm})$} & Flexion & $1.51 \pm 1.51$ & $0.28 \pm 1.69$ & -2.112 & $0.044^{*}$ \\
\hline & Extension & $1.46 \pm 2.08$ & $0.08 \pm 1.21$ & -2.191 & $0.037^{\star}$ \\
\hline & Rt Flexion & $1.08 \pm 1.65$ & $-0.08 \pm 1.98$ & -1.746 & 0.092 \\
\hline & Lt Flexion & $1.40 \pm 2.17$ & $-0.16 \pm 2.05$ & -1.999 & 0.055 \\
\hline & Rt Rotation & $1.41 \pm 2.47$ & $-0.36 \pm 0.75$ & -2.573 & $0.016^{*}$ \\
\hline & Lt Rotation & $1.10 \pm 1.86$ & $-0.49 \pm 2.18$ & -2.148 & $0.041^{*}$ \\
\hline
\end{tabular}

CROM: Cervical range of motion, HRA: Head repositioning accuracy.

${ }^{*} p<0.05$.

\section{2. 목의 근피로도 유발 전후 집단 간 관절가동범위와 고유수용성 감각 비교}

FHP군과 정상군에서 목에 근피로도를 유발하기 전과 후 목의 관절 가동범위 변화량을 비교한 결과 관절가동범위의 변화량은 모든 동 작에서 유의한 차이가 없었으나 $(\mathrm{p}>0.05)$, 고유수용성 감각 변화량을 비교한 결과 굽힘, 폄, 양측 돌림에서 유의한 차이가 있었고 $(\mathrm{p}<0.05)$, 양측 옆굽힘에서 유의한 차이가 없었다( $\mathrm{p}>0.05)$ (Table 2).

\section{고 찰}

본 연구에서는 앞쪽머리자세의 유무에 따라 목의 근육 피로를 유발 한 후 목의 관절가동범위와 고유수용성 감각의 변화를 알아보고자 하였다. 그 결과 목의 근피로도 유발 전후 FHP군에서는 관절가동범 위와 고유수용성 감각에서 유의하게 감소하였고, 정상군에서는 관 절가동범위는 유의하게 감소하였지만, 고유수용성 감각에서 유의한 차이가 없었다. 또한, 몸의 근피로도 유발 전후 관절가동범위와 고유 수용성 감각 변화량에 대한 집단 간 비교에서 관절가동범위의 변화 량은 FHP군이 정상군에 비해 더 높게 감소하였고, 고유수용성 감각 의 변화량은 목의 굽힘, 폄, 양측 돌림에서 유의한 차이가 있었으며, 양측 옆굽힘에서 유의한차이가 없었다.

선행연구에서 건강한 성인과 만성 피로 증후군을 가진 성인을 비 교하여 관절가동범위를 평가한 결과 건강한 성인보다 만성 피로 증 후군을 가진 성인에서 관절가동범위의 손상이 더 많다고 하였다. ${ }^{29}$ 또한, Descarreaux 등 ${ }^{30}$ 은 엉덩관절 및 척추의 폄근의 피로가 굽힘-이 완 현상의 매개변수에 미치는 영향과 이러한 변화가 허리-골반 역학 의 변화에 의해 유발되는지 조사한 결과 엉덩관절 및 척추 폄근의 피 로가 허리-골반 리듬과 굽힘-이완 현상의 매개 변수를 변화시키고,
근육의 피로로 인하여 엉덩관절의 굽힘 각도가 감소했다고 하였다. 본 연구의 결과는 FHP군과 정상군 모두 목 근육 피로 유발 전과 비교 하여 유발 후 관절가동범위가 감소하였고, 이는 여러 선행연구들의 결과와 일치한다.

Lee 등기는 느리게 적응하는 관절 기계수용체가 근육이 피로했을 때 어깨 고유수용성 감각에 미치지 않았다고 하였다. 하지만, Voight 등 32 은 우세 팔과 어깨 고유수용성 감각의 피로 및 관계의 영향에 대 한 연구에서 피로가 능동 및 수동 운동 시 관절의 재배치 능력을 크 게 감소시켰다고 하였다. 또한, Carpenter 등 33 은 근육 피로 후 고유수 용성 감각 감소가 운동 능력 저하와 어깨 기능장애에 영향을 미칠 수 있다고 하였다. Sharpe 등 34 은 피로가 발생하면 운동제어가 서투르고 정확도가 감소한다고 하였고, Skinner 등 35 은 운동 감각의 신경 메커 니즘 변화가 근육 수용체의 피로에 의한 변화로 인해 나타난다고 하 였다. 이처럼 피로가 고유수용성 감각에 영향을 미치는지에 대하여 논란이 있지만, 일부 연구에서는 근육 피로 후 고유수용성 감각 피드 백이 감소하여 위치 감각의 정확성이 떨어진 것으로 나타났다. 본 연 구에서 실험 전후 고유수용성 감각 비교에서 FHP군은 실험 전보다 실험 후 유의하게 감소하였고, 정상군은 유의한 차이가 없었다. 이는 장기적인 목의 근육 피로를 유발하는 앞쪽머리자세를 가진 FHP군 에서 피로 유발 시 정상군 보다 더 큰 목의 근육 피로를 유발시킨 것 으로 사료된다.

이전 연구에서 앞쪽머리자세는 영향을 받는 근육 방추들을 통해 관절 위치 감각에 영향을 미칠 수 있다고 하였고, ${ }^{36}$ 또 다른 연구에서 는 앞쪽머리자세를 가진 군이 정상 자세 군보다 고유수용성 감각에 서 더 큰 오차를 보여 관절 위치 감각이 감소했다고 하였다. ${ }^{37}$ 또한, Reddy 등 ${ }^{14}$ 은 목 근육의 피로가 굽힘과 폄에서 유의한 차이가 있었다 고 하였으며, Pinsault 등 ${ }^{38}$ 은 목 근육의 피로가 목의 고유수용성 감각 
을 저하시킨다고 하였다. Lee 등 39 은 앞쪽머리자세가 관절 위치 감각 에 영향을 미쳐 정상 자세와 비교하여 굽힘, 폄, 양측 돌림에서 재배 치 오류에 큰 차이가 있다고 하였다. 본 연구 결과에서도 FHP군과 정 상군의 그룹 간 고유수용성 감각 비교에서 굽힘과 폄, 양측 돌림은 $\mathrm{FHP}$ 군이 정상군에 비해 더 크게 증가하였으며, 선행연구들의 결과 를 볼 때 피로에 약한 앞쪽머리자세에서 피로 유발 시 고유수용성 감 각의 저하가 더 크게 나타난 것으로 사료된다. 하지만 양측 옆굽힘에 서는 집단 간 유의한 차이가 없었는데 이는 목의 옆굽힘에 일차적으 로 작용하는 목빗근과 목갈비근이 주어진 피로 유발에 크게 영향을 받지 않았기 때문이라 사료된다.

본 연구는 앞쪽머리자세의 유무에 따라 목의 근육 피로를 유발한 후 목의 관절가동범위와 고유수용성 감각의 변화를 알아보았다. 근 육에 피로를 주었을 때, 관절가동범위에 영향을 미치고, 앞쪽머리자 세를 가졌을 때, 관절가동범위 및 고유수용성 감각에 영향을 미친다. 또한, 앞쪽머리자세와 정상 성인의 근육 피로 전후의 변화량을 비교 했을 때, 고유수용성 감각에서 유의한 차이가 나는 것을 확인하였다. 이러한 결과로 볼 때, 앞쪽머리자세를 유발하는 자세 및 행동이 근육 의 피로를 지속적으로 주게 되어 관절가동범위나 고유수용성 감각 에 문제가 생기게 된다. 따라서 앞쪽머리자세가 목 근육의 피로 발생 시 더욱 관절가동범위와 고유수용성 감각을 감소시키기 때문에 자 세를 교정함으로써 목 근육의 피로로 인한 임상적 문제의 발생을 예 방할 수 있을 것이며 앞쪽머리자세에 대한 임상적 치료에 적용할 수 있을 것이다. 본 연구의 제한점은 첫째, 실험에 참여한 대상자 수가 적 고, 젊은 성인을 대상으로 했기 때문에 전체 연령의 결과로 일반화하 기 어렵다. 둘째, 피로 유발 후 고유수용성 감각에 대한 측정을 단일 실험으로 수행했기 때문에 학습효과가 발생할 수 있다. 따라서 앞으 로의 연구에서는 본 연구의 제한점을 보완하여 대상자 수를 늘리고 연령대를 다양하게 하여 일반화시키고, 피로 유발 방법 변경 및 새로 운 치료 프로토콜을 통한 치료 효과를 알아보는 연구가 필요할 것이다.

\section{REFERENCES}

1. Haughie LJ, Fiebert IM, Roach KE. Relationship of forward head posture and cervical backward bending to neck pain. J Man Manip Ther. 1995; 3(3):91-7.

2. Kang JH, Park RY, Lee SJ et al. The effect of the forward head posture on postural balance in long time computer based worker. Ann Rehabil Med. 2012;36(1):98.

3. Garrett TR, Youdas JW, Madson TJ. Reliability of measuring forward head posture in a clinical setting. J Orthop Sports Phys Ther. 1993;17 (3):155-60.

4. Salahzadeh Z, Maroufi N, Ahmadi A et al. Assessment of forward head posture in females: observational and photogrammetry methods. J Back Musculoskelet Rehabil. 2014;27(2):131-9.
5. Nam KS, Kwon JW. The effects of head position in different sitting postures on muscle activity with/without forward head and rounded shoulder. J Korean Phys Ther. 2014;26(3):140-6.

6. Reece A. Investigating the effects of subclinical neck pain, cervical treatment, and neck muscle fatigue on wrist joint position sense. Brock University. Dissertation of Master's Degree. 2019.

7. Harman K, Hubley-Kozey CL, Butler H. Effectiveness of an exercise program to improve forward head posture in normal adults: a randomized, controlled 10-week trial. J Man Manip Ther. 2005;13(3):163-76.

8. Lee SM, Lee CH, O'Sullivan D et al. Clinical effectiveness of a pilates treatment for forward head posture. J Phys Ther Sci. 2016;28(7):200913.

9. Peolsson A, Kjellman G. Neck muscle endurance in nonspecific patients with neck pain and in patients after anterior cervical decompression and fusion. J Manipulative Physiol Ther. 2007;30(5):343-50.

10. Enoka RM, Stuart DG. Neurobiology of muscle fatigue. J Appl Physiol. 1992;72(5):1631-48.

11. Alsén P, Brink E, Persson LO. Living with incomprehensible fatigue after recent myocardial infarction. J Adv Nurs. 2008;64(5):459-68.

12. Portero R, Quaine F, Cahouet V et al. Influence of cervical muscle fatigue on musculo-tendinous stiffness of the head-neck segment during cervical flexion. PloS one. 2015;10(9):e0139333.

13. Kwon MS, Lee SH, Cho IR et al. Electromyography comparison of normal chair-desk system and assistant chair-desk system on fatigue. J Phys Ther Sci. 2015;27(10):3171-5.

14. Reddy RS, Maiya AG, Rao SK. Effect of dorsal neck muscle fatigue on cervicocephalic kinaesthetic sensibility. Hong Kong Physiother J. 2012;30(2):105-9.

15. Stapley PJ, Beretta MV, Dalla Toffola E et al. Neck muscle fatigue and postural control in patients with whiplash injury. Clin Neurophysiol. 2006;117(3):610-22.

16. Schieppati M, Nardone A, Schmid M. Neck muscle fatigue affects postural control in man. Neuroscience. 2003;121(2):277-85.

17. Al SAif AA, Al SenAny S. Determine the effect of neck muscle fatigue on dynamic visual acuity in healthy young adults. J Phys Ther Sci. 2015;27 (1):259-63.

18. Schmid M, Schieppati M. Neck muscle fatigue and spatial orientation during stepping in place in humans. J Appl Physiol. 2005;99(1):141-53.

19. Weon JH, Oh JS, Cynn HS et al. Influence of forward head posture on scapular upward rotators during isometric shoulder flexion. J Bodyw Mov Ther. 2010;14(4):367-74.

20. Stanton TR, Leake HB, Chalmers KJ et al. Evidence of impaired proprioception in chronic, idiopathic neck pain: systematic review and metaanalysis. Phys Ther. 2016;96(6):876-87.

21. Fitz-Ritson D. Phasic exercises for cervical rehabilitation after "whiplash" trauma. J Manipulative Physiol Ther. 1995;18(1):21.

22. Jull G, Falla D, Treleaven J et al. Retraining cervical joint position sense: the effect of two exercise regimes. J Orthop Res. 2007;25(3):404-12.

23. Revel M, Minguet M, Gergoy P et al. Changes in cervicocephalic kinesthesia after a proprioceptive rehabilitation program in patients with neck pain: A randomized controlled study. Arch Phys Med Rehabil. 1994;75 (8):895-9.

24. Fernández-de-Las-Peñas C, Cuadrado M, Pareja J. Myofascial trigger points, neck mobility and forward head posture in unilateral migraine. 
Cephalalgia. 2006;26(9):1061-70.

25. Ryu H. Effects of core exercise and neck stabilizing exercise on proprioception and balance in children with cerebral palsy due to premature birth. Daegu University. Dissertation of Doctorate Degree. 2015.

26. Lee H. The effects of the cervical stabilizing exercise on cervical proprioception, shoulder strength and hand grip strength. Daegu University. Dissertation of Master's Degree. 2012.

27. Lee H, Nicholson LL, Adams RD. Neck muscle endurance, self-report, and range of motion data from subjects with treated and untreated neck pain. J Manipulative Physiol Ther. 2005;28(1):25-32.

28. Nimbarte AD, Zreiqat MM, Chowdhury SK. Cervical flexion-relaxation response to neck muscle fatigue in males and females. J Electromyogr Kines. 2014;24(6):965-71.

29. Rowe PC, Marden CL, Flaherty MA et al. Impaired range of motion of limbs and spine in chronic fatigue syndrome. J Pediatr. 2014;165(2):360-6.

30. Descarreaux M, Lafond D, Cantin V. Changes in the flexion-relaxation response induced by hip extensor and erector spinae muscle fatigue. BMC Musculoskelet Disord. 2010;11(1):112.

31. Lee HM, Liau JJ, Cheng CK et al. Evaluation of shoulder proprioception following muscle fatigue. Clin Biomech. 2003;18(9):843-7.

32. Voight ML, Hardin JA, Blackburn TA et al. The effects of muscle fatigue on and the relationship of arm dominance to shoulder proprioception. J Orthop Sports Phys Ther. 1996;23(6):348-52.

33. Carpenter JE, Blasier RB, Pellizzon GG. The effects of muscle fatigue on shoulder joint position sense. Am J Sports Med. 1998;26(2):262-5.

34. Sharpe MH, Miles TS. Position sense at the elbow after fatiguing contractions. Exp Brain Res. 1993;94(1):179-82.

35. Skinner H, Wyatt M, Hodgdon J et al. Effect of fatigue on joint position sense of the knee. J Orthop Res. 1986;4(1):112-8.

36. Yong MS, Lee HY, Lee MY. Correlation between head posture and proprioceptive function in the cervical region. J Phys Ther Sci. 2016;28(3): 857-60.

37. Ha SY, Sung YH. A temporary forward head posture decreases function of cervical proprioception. J Exerc Rehabil. 2020;16(2):168.

38. Pinsault N, Vuillerme N. Degradation of cervical joint position sense following muscular fatigue in humans. Spine. 2010;35(3):294-7.

39. Lee MY, Lee HY, Yong MS. Characteristics of cervical position sense in subjects with forward head posture. J Phys Ther Sci. 2014;26(11):1741-3. 